\title{
Assesment of cardiac volumes in children with congenital heart disease using a 3D dual cardiac phase technique and a new segmentation tool
}

\author{
Tarique Hussain*1, Hannah Bellsham-Revell ${ }^{1}$, Sergio Uribe ${ }^{2}$, Aaron Bell1 ${ }^{1}$, \\ Reza Razavi ${ }^{1}$, Phillip Beerbaum ${ }^{1}$, Isra Valverde ${ }^{1}$, Tobias Schaeffter ${ }^{1}$ and \\ Gerald Greil ${ }^{1}$
}

\author{
Address: ${ }^{1}$ King's College London, London, UK and ${ }^{2}$ Pontificia Universidad Catolica de Chile, Santiago, Chile
}

* Corresponding author

from 13th Annual SCMR Scientific Sessions

Phoenix, AZ, USA. 21 -24 January 2010

Published: 21 January 2010

Journal of Cardiovascular Magnetic Resonance 2010, I2(SuppI I):P2 doi:I0.I I86/1532-429X-I2-SI-P2

This abstract is available from: http://jcmr-online.com/content/I2/SI/P2

(c) 2010 Hussain et al; licensee BioMed Central Ltd.

\section{Introduction}

For children with complex congenital heart disease (CHD), the decision regarding univentricular or biventricular surgical repair may depend on accurate ventricular volume assessment. We have previously shown that threedimensional (3d) whole-heart imaging acquired during end-systole and end-diastole (dual-phase) during one free-breathing MRI examination, when combined with semi-automatic analysis, may be more reproducible in calculating ventricular volumes than standard techniques (Uribe et al, 2008). We describe here, for the first time, use of $3 \mathrm{~d}$ dual-phase imaging in children with complex CHD.

\section{Purpose}

To show 3d dual-phase imaging is feasible in children with complex CHD despite high heart rates.

\section{Methods}

The dual-phase sequence was used alongside standard $2 \mathrm{~d}$ multi-slice cine in ten children with complex CHD (table 1). Analysis required a new semi-automatic segmentation tool which incorporates multiplanar reformatting and volume rendering to identify ventricular boundaries (ViewForum, Philips Healthcare, Figure 1). Two observers independently assessed end-diastolic and end-systolic ventricular volumes using both standard $2 \mathrm{~d}$ cine with manual segmentation and new $3 \mathrm{~d}$ dual-phase with semi- automatic segmentation. If applicable, stroke volumes obtained were compared to phase contrast results. BlandAltman was used to assess agreement and Pearson's coefficient for correlation.

\section{Results}

The mean age was 3 yrs (range 3 months-9 yrs) and heart rate range was 58-139 bpm. Volumetric analysis was feasible in all cases. Inter- and Intra-observer variability was similar for both methods. For $2 \mathrm{~d}$ cine, acquired resolution was $1.8 \mathrm{~mm} \times 1.8 \mathrm{~mm}$; slice thickness 5 to $6 \mathrm{~mm} \&$ temporal resolution $30 \mathrm{~ms}$ (20-40 phases). For $3 \mathrm{~d}$ dual-phase, acquired resolution was $1.3 \mathrm{~mm}$ isotropic \& temporal resolution $60 \mathrm{~ms}$ ( 2 phases). Bland-Altman (Figure 2A (systole), 2B (diastole)) showed excellent agreement between standard $2 \mathrm{~d}$ cine and $3 \mathrm{~d}$ dual-phase analyses (also, correlation 0.96(systole) and 0.93(diastole)). Similarly, Bland Altman for phase contrast stroke volume showed slightly better agreement with $3 \mathrm{~d}$ dual-phase (Figure 2C) than with standard 2d cine (Figure 2D) (correlation 0.90 and 0.88 respectively). 
Table I: Patient diagnoses

\begin{tabular}{|c|c|c|}
\hline Diagnosis & $\begin{array}{l}\text { Which Ventricle } \\
\text { Segmented }\end{array}$ & $\begin{array}{l}\text { Number of Patients } \\
\text { with given } \\
\text { diagnosis }\end{array}$ \\
\hline Repaired Pulmonary Atresia, VSD, Major Aorto-Pulmonary Collaterals with severely dilated RV & RV & 2 \\
\hline Hypoplastic Left Heart Syndrome; Status Post Glenn Procedure & RV & I \\
\hline Hypoplastic Left Heart Syndrome; Status Post Norwood Procedure & RV & I \\
\hline $\begin{array}{l}\text { Left Atrial Isomerism, Univentricular AV connection, Solitary RV, Aortic Atresia, Dextrocardia, } \\
\text { Azygous continuation. Status Post Norwood }\end{array}$ & RV & I \\
\hline $\begin{array}{l}\text { Transposition of Great Arteries, VSD, Pulmonary Stenosis, Dextrocardia, Status Post Rastelli } \\
\text { Procedure }\end{array}$ & RV & 1 \\
\hline $\begin{array}{l}\text { Situs Solitus, AV concordance, VA disconcordance, Dextrocardia, Unbalanced AVSD with } \\
\text { Rudimentary Left Ventricle, Status Post Glenn }\end{array}$ & RV & I \\
\hline $\begin{array}{l}\text { Situs Solitus, AV concordance, Pulmonary Atresia with Aorta from RV, Unbalanced AVSD with } \\
\text { Rudimentary Left Ventricle, Status Post Modified Blalock-Thomas-Taussig shunt }\end{array}$ & RV & I \\
\hline Unrepaired Tetralogy of Fallot, with Major Aorto-Pulmonary Collaterals. & RV & 1 \\
\hline Double Inlet Left Ventricle, Pulmonary Atresia, Status Post Glenn Procedure & LV & I \\
\hline
\end{tabular}

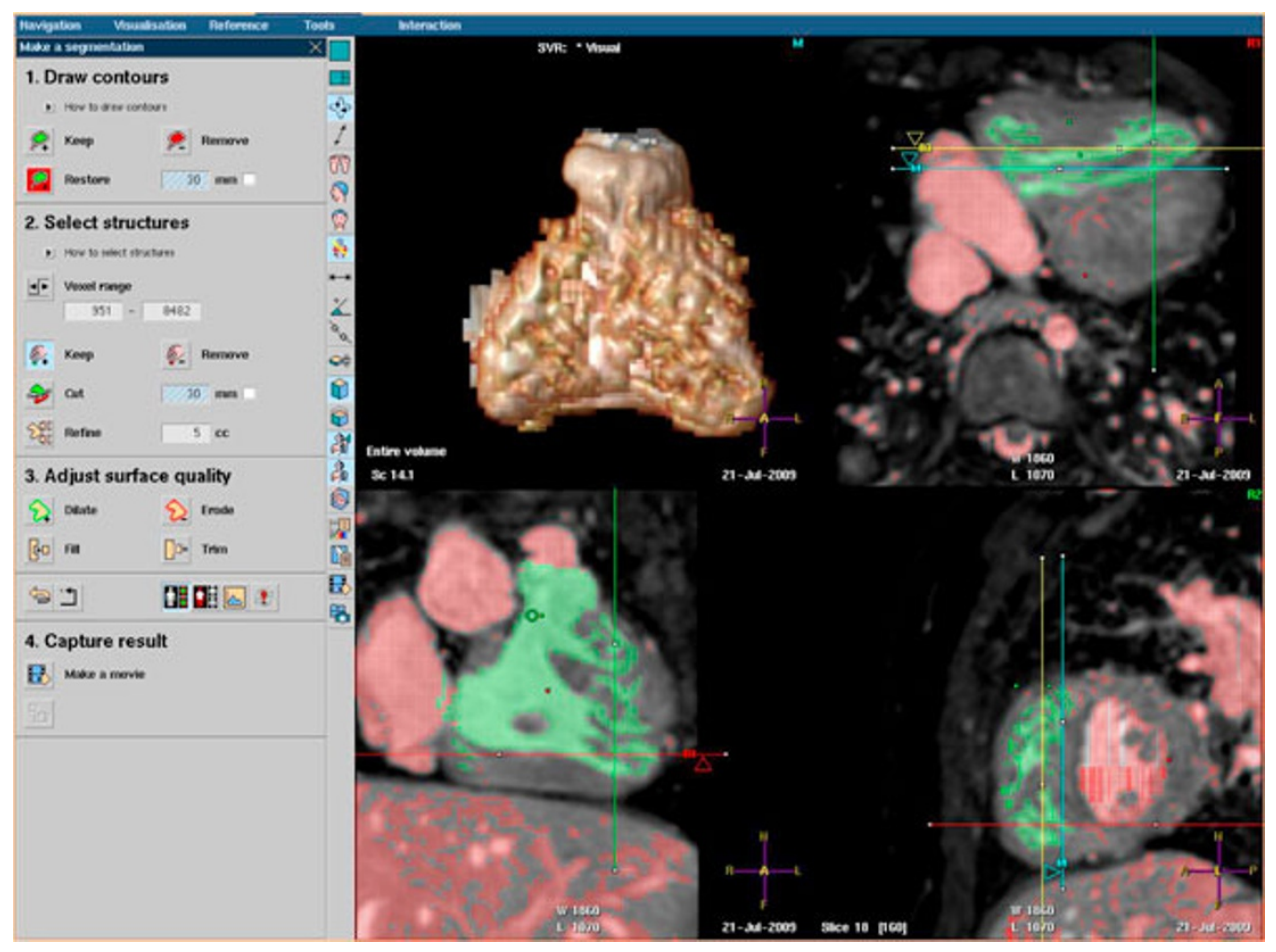

Figure I 

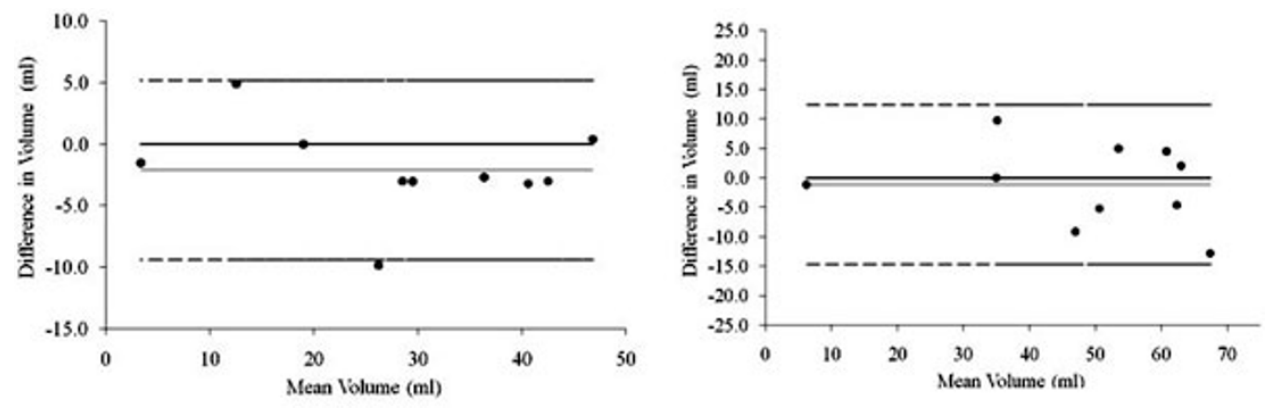

\section{A}

B
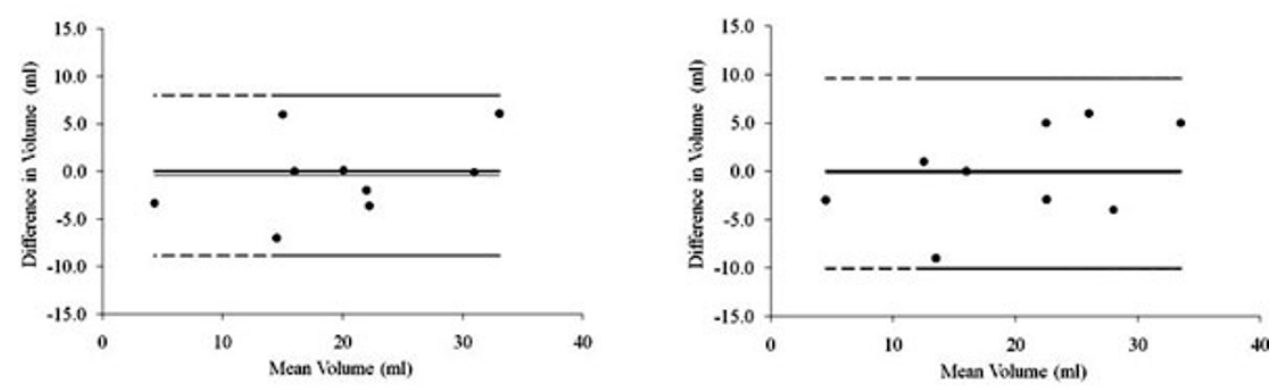

C

D

Figure 2

\section{Conclusion}

Standard ventricular analysis involves manual segmentation of cross-sectional cine images acquired over several breath-holds. This can have problems with slice misalignment. Furthermore, lack of isotropic resolution (by using thick slices which move during the cardiac cycle) makes definition of atrio-ventricular \& ventriculo-arterial boundaries difficult. Therefore, acquisition and segmentation relies on operator experience. We believe that $3 \mathrm{~d}$ dual-phase imaging with semi-automatic analysis overcomes these issues. This study demonstrates that $3 \mathrm{~d}$ dualphase imaging can successfully be performed even in very young children with complex CHD. Reliable and valid volumetric analysis was possible using the new semi-automatic segmentation technique.
Publish with Bio Med Central and every scientist can read your work free of charge

"BioMed Central will be the most significant development for disseminating the results of biomedical research in our lifetime. "

Sir Paul Nurse, Cancer Research UK

Your research papers will be:

- available free of charge to the entire biomedical community

- peer reviewed and published immediately upon acceptance

- cited in PubMed and archived on PubMed Central

- yours - you keep the copyright

Submit your manuscript here:

http://www.biomedcentral.com/info/publishing_adv.asp

BioMedcentral 